\title{
THE REFLEX RESERVE
}

\author{
Peter R. Killeen
}

\author{
ARIZONA STATE UNIVERSITY
}

At once in his magnificent The Behavior of Organisms (1938), B. F. Skinner provided a theoretical basis for a science of behavior and denied that his approach was theoretical. His view of science was that of Mach; theoretical terms were but shorthand, and the goal of science was economy of description. Thus he could introduce "states" such as hunger and emotion as long as they paid their way in explanatory utility. This process is illustrated on p. 24, where he properly argues that "The notion of an intermediate state [such as a drive or emotion] is valuable when (a) more than one reflex is affected by the operation, and (b) when several operations have the same effect." But, because such constructs are merely expedients, they are neither necessary nor is their elucidation the core of a science. They may be casually discarded for representations of greater economy, or even for no representations at all if it is decided that it is not worth the bother teaching shorthand. ("One of the few groups of well formulated pure intervening variables in psychology, Skinner's concepts of drive, emotion, and reflex reserve, are eliminated by their creator, precisely on the grounds that having no surplus meaning they can be eliminated" [Zuriff, 1985, p. 95]; see Pauly's [1987] fascinating history of Skinner's early intellectual environment in which parsimony, control, and technology were the dominant leitmotifs.) In The Behavior of Organisms Skinner introduced a number of theoretically important constructs, most of which he subsequently discarded. Although I shall hazard some guesses about why he discarded them, it is my purpose here to analyze what it was that he threw away, and what might have been made of it.

One cannot understand The Behavior of Organisms without recognizing that its purpose was the elucidation of two key constructs,

I thank S. R. Coleman and J. McDowell for comments on an earlier draught of the manuscript. reflex strength and the reflex reserve. His was a system, and he criticized other accounts, such as Hull's, because their constructs were ad hoc. What made Skinner's constructs germane was their parsimony and organic integrity. This will be illustrated by developing a picture of the richest construct, the reserve. It will be a literal picture, because Skinner must had had such a one in mind as he developed his theory. Had he drawn this picture for his audience, it would have communicated his theory much more effectively than the verbal descriptions and constraints developed over the course of the book. But it is easy to see why he might have demurred, because his model was a hydraulic one, not unlike the systems of reservoirs and flush devices used to illustrate psychodynamic and ethological theories. Even in the 1930s such civil engineering models would have been greeted with condescension; in our high-tech age the response would be incredulity. (Although I suspect that many of those left frigid by such a model would melt at the sight of an equation.) Such left-hemisphere chauvinism reveals an unfamiliarity with the most effective methods of science.

Physical models have always played an important role as structures around which to organize the constraints of a theory. Once those have been elaborated the original picture may be discarded or retained. Which role the model will play-scaffolding or superstructure-is often not known until the building nears completion. Thus Faraday's picture of vortices was the basis of Maxwell's equations of electromagnetic radiation, which then superseded the picture; Einstein's falling elevator was displaced by the general field equations; Feyneman's diagrams (themselves pictorial shorthand for equations) were retained as a useful part of quantum mechanics, and actually displaced a formally identical (it was later shown) mathematical model. Simple harmonic motion is commonly pictured 
in terms of a spring and mass, or of a pendulum; however, it is a ubiquitous model for systems in which no physical spring can exist, such as vibrating molecules. The Bohr planetary model of the atom formed the basis for important advances in atomic physics. And so on.

This review draws the picture that Skinner was reluctant to show; it goes on to develop the equations that the model forces (Skinner developed a mathematical model de facto, despite his protestations that such development was premature). Finally it compares those equations with the equations deriving from contemporary models.

\section{REFLEX STRENGTH AND THE REFLEX RESERVE}

The Behavior of Organisms treats both respondent and operant conditioning. "The notion [of reflex strength and the reflex reserve] applies to all operations that involve the elicitation of the reflex and to both operant and respondent behavior, whether conditioned or unconditioned" (pp. 26-27). The present analysis will be limited to operant conditioning because the constraints developed by Skinner's experiments bear most directly on that.

Although Skinner lists the operations that affect strength early in the book, it is on page 58 that we are given the main dependent variable: "The rate of responding is the principal measure of the strength of an operant." But strength is only part of the story; staying power is the other. And these parts interact. Response rate changes over time as a function of the number of responses held in a reserve, moderated by other factors such as drive, emotion, and the stimulus field. For unconditioned reflexes the number in reserve is constantly being restored. "In conditioned reflexes the reserve is built up by the act of reinforcement, and extinction is essentially a process of exhaustion comparable with fatigue" (p. 27). A critically important assumption is the relation of strength to the size of the reserve: "The strength of a reflex is proportional to its reserve" (p. 27). But this should be prefaced with ceteris paribus, for various operations can alter the size of the constant of proportionality: "All operations that involve elicitation affect the reserve directly.... Conditioning increases it; elicitation and fatigue decrease it. The other operations (which [affect not just a single reflex but] groups of reflexes) change the proportionality between the reserve and strength. Facilitation and certain kinds of emotion increase the strength, while inhibition and certain other kinds of emotion decrease it without modifying the reserve. The operations that control the drive also affect the proportionality factor." (p. 27). He later acknowledges that "there is no simple relation between these two measures [strength and reserve]. . because of the interposition of the limited 'immediate' reserve" (pp. 85, 86). The immediate reserve mediates compensatory increases in rate following interruptions of responding and also seems to limit the rate of responding.

So far, so good; our memory is strained but not overloaded. But in the next few pages an additional reserve is introduced: "In a phasic respondent the refractory phase suggests a smaller subsidiary reserve which is either completely or nearly completely exhausted with each elicitation.... The rate of elicitation of an operant exhibits a similar effect" (p. 28, emphasis added). Throughout the book experimental results are interpreted in terms of their effects on the reserve or on the immediate reserve, or on the constant of proportionality relating these to response strength. How are these ancillary reserves connected to the main reserve? At what points do various operations affect the proportionality? Are there limits to these reserves? How are they replenished? How do we keep all this straight? Should we take it seriously? How is this complicated plumbing related to the streamlined Skinner we grew up on?

\section{A PHYSICAL MODEL}

We should take the reserve seriously, as Skinner did, and upon inspection we find the structure to be sound. "In one sense the reserve is a hypothetical entity. ... But I shall later show in detail that a reserve is clearly exhibited in all its relevant properties.... The reserve is consequently very near to being directly treated experimentally" (p. 26; see Coleman, 1984, and McDowell, 1988, for discussions of Skinner's Realist tendencies). But if we are to keep up with Skinner's construction, we need to see the blueprint. That is provided in Figure 1. It is important 
to remember that Skinner did not have this in hand when he started his work. As data were collected they required modifications of the original conception. It is very difficult to maintain integrity of original structures as necessary modifications pile up. I believe that it was the extreme intellectual stress of doing so that caused Skinner to eventually abandon this model.

The model is drawn as three reservoirs containing the reserve. (Skinner used the term reserve to refer to the contents of the reservoirs-"I shall speak of the total available activity as the reflex reserve," p. 26-and did not refer to the containers at all. The reservoirs are drawn for expository purposes, but it is unlikely that Skinner would have favored such a reification. Although the reservoirs are logically supererogatory, they are conceptually and pedagogically essential.) The reservoirs are labeled Primary, Secondary, and Tertiary, and respectively "contain" the reserve (also termed the whole reserve or the total reserve), the immediate reserve ("which is contributed to from the total reserve"; p. 85), and the subsidiary reserve.

The sizes of the reservoirs are not drawn to scale. The primary reservoir is large enough to contain all of the potential responses that will be emitted in extinction after continuous reinforcement-hundreds of responses. The secondary reservoir must contain all of the responses that will be emitted in compensatory rate increases-on the order of dozens of responses. The tertiary reservoir "is either completely or nearly completely exhausted with each elicitation" (p. 28), so that its size is on the order of a single response.

\section{Filling the Reservoirs}

How are the reservoirs filled? "In conditioned reflexes the reserve is built up by the act of reinforcement" (p. 27); "Reinforcement ... establishes the potentiality of a subsequent extinction curve, the size of which is a measure of the extent of conditioning" (p. 85). This process of filling the reservoir is not further detailed by Skinner, but may be depicted by the piston in the top of the figure. That engine is powered by drive, which operates the machinery of reinforcement to place potential responses in the reservoir. Reinforcement that occurs under conditions of low drive contributes to the reserve "but the value is scarcely significant" (p. 401). Other operations, such as imposing a delay between a response and reinforcer, may also decrease the number of responses added to the reserve (p. 145).

In his Figure 15 (and others throughout the book) Skinner graphed "the reserve created by a single reinforcement" (p. 86), an extinction curve following the reinforcement of one response. How should we measure the "size" of that curve? Skinner suggested either the area of the cumulative record or its height. But upon consideration we recognize that it cannot be area-that can be arbitrarily increased by leaving the recorder on after the animal has ceased responding. The dimension of the area measure is response-seconds, which is nowhere mentioned as a relevant variable. The height is measured in responses, the same dimension in which the reserve is measured (p. 229), so that is a better candidate. But the height changes over time. It is the asymptotic height of the extinction curve after an indefinitely long time that provides the desired measure of the size of the reserve. (This measure must be corrected for spontaneously occurring responses not associated with conditioning. Skinner himself made this correction for "operant level" by estimating the rate of those spontaneous responses, representing that as a linear cumulative response record, and subtracting it from the obtained record to get an uncontaminated picture of the exhaustion of the reserve; p. 89).

We know that there are limits to the extent to which additional reinforcers will condition a response. "There is an upper limit to the size of the reserve, and successive reinforcements are less and less effective in adding to the total as the maximal value is approached" (p. 90). This "decreasing marginal utility" of reinforcers is an important fact about conditioning. Reinforcement of a single lever press by a rat will generate a reserve containing between 50 and 100 responses. The largest extinction curve following continuous reinforcement that Skinner had seen contained just over 200 responses, and that rat had received 250 reinforcers (his Figure 17). The finite maximal size of the reserve is represented in Figure 1 by making the primary reservoir a finite and closed container.

For what type of physical system does input become more and more difficult as full capacity 


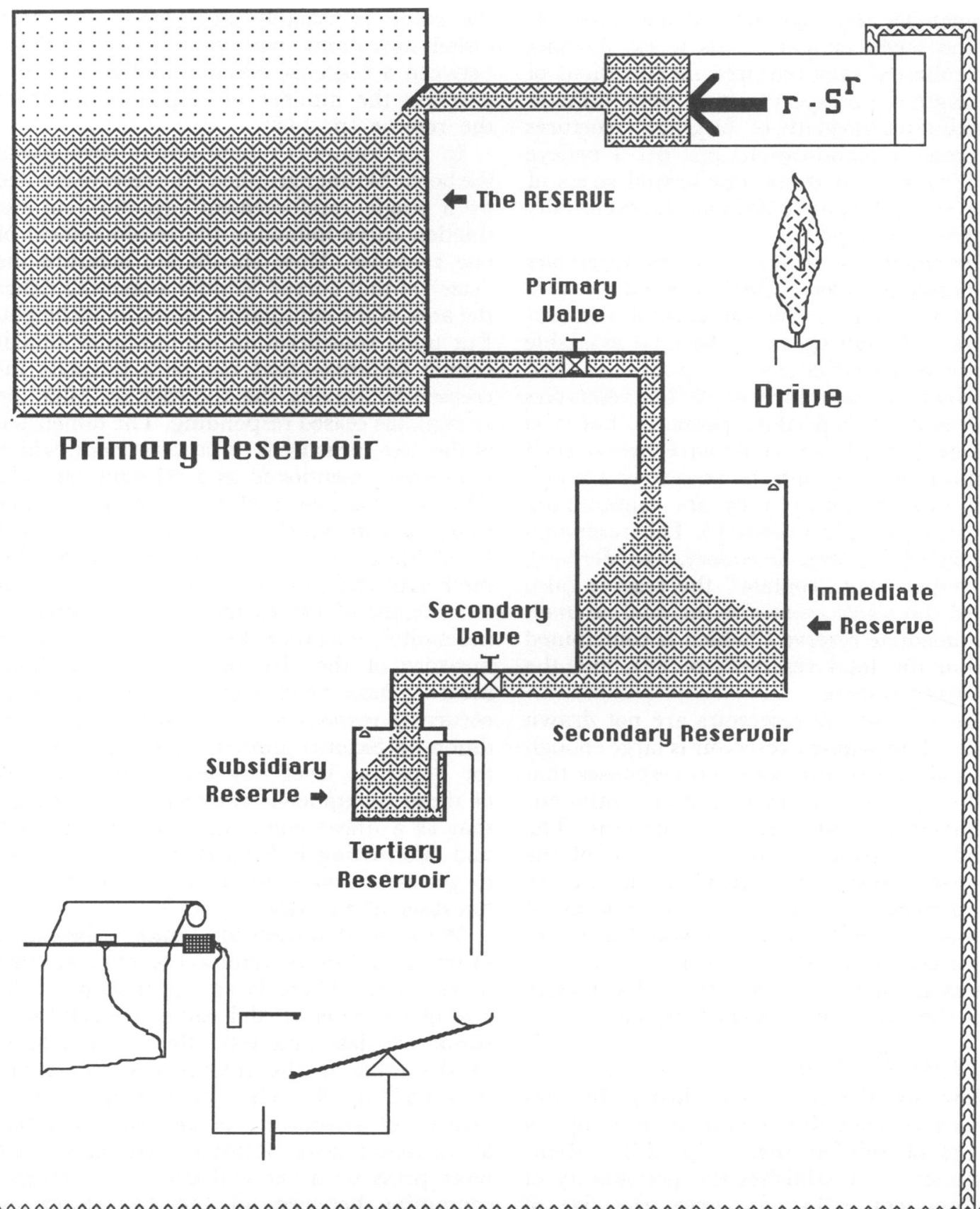

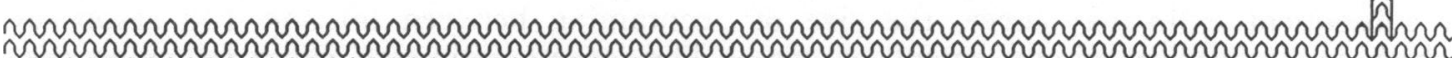

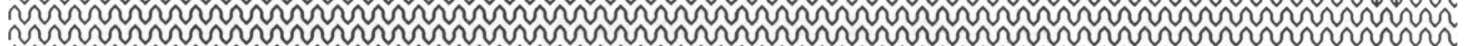

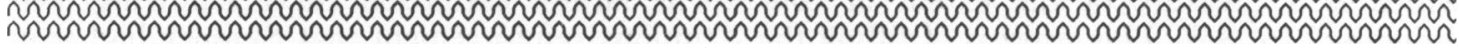

Fig. 1. The reflex reserve.

is reached? We can think of a number of such systems (e.g., as a capacitor approaches its maximum charge it becomes more difficult to add electrons to it). To maintain the hydraulic metaphor, we need merely close the reservoir so that input must compress a gas in the closed space above it. The gas laws then show that each successive input meets increasing resistance as the reservoir becomes full. Alternatively, we might construct the 
primary reservoir as very tall and narrow, with the injection port at the bottom. Then each additional injection would have to raise a larger head above it, and thereby be proportionately less effective. The laws deriving from those two constructions would be isomorphic, so that the choice of the physical models becomes one of taste. That choice may in the future be constrained by elaborations of the model that account for new data or that more adequately embrace existing data.

\section{Draining the Reservoirs}

How are the reservoirs emptied? Extinction and fatigue decrease the reserve (p. 27). The reserve may also decrease very slowly over time, but that "forgetting" process is not to be confused with the decrease in reserve due to the elicitation of the response (pp. $91 \mathrm{ff}$ ). To allow for forgetting, the reservoir should be permeable; that is, it should leak.

How quickly will the reservoir be drained by responding? "Rate of responding is the principal measure of the strength of an operant" (p. 58); "momentary strength is proportional to the reserve" (p. 26); together these laws permit us to infer that "As responses occur the reserve is drained and the rate declines" (p. 84). Our reservoirs capture this property: The force on the medium at the bottom is proportional to the head above it, and the speed of its exit from the reserve is proportional to that force.

Exhaustion of the reserve is not instantaneous:

The total reserve of an operant does not pour
out at once as soon as the opportunity arises;
the rate of elicitation is relatively slow and
presumably depends upon a ... subsidiary
reserve exhausted at each single occurrence.
We may regard the emission of an operant
response as occurring when the subsidiary
reserve reaches a critical value. A second re-
sponse cannot occur until the subsidiary reserve
has been restored to the same value. The rate
of restoration is again a function of the total
reserve. (p. 28)

Cast in electronic terms, Skinner has described a relaxation oscillator. How is this notion captured in a hydraulic model? The picture of the siphoned tertiary reserve in Figure 1 is one way of doing so. When the tertiary reserve reaches the height through which the siphon exits, the reserve is drained down to the level of the bottom of the siphon, and must refill to the top before another response exhausts the reservoir. Its rate of restoration will depend on the head above it in the primary and secondary reservoirs.

This tertiary reservoir did not play an important role in Skinner's model: "I shall not need to refer again to the subsidiary reserve.... In operant behavior the notion is carried adequately by that of a rate" ( $p$. 28 ). Of course, response rate plays a critical role as the principal measure of response strength: "The main datum to be measured in the study of the dynamic laws of an operant is the length of time elapsing between a response and the response immediately preceding it or, in other words, the rate of responding"; "Rate of responding is the principal measure of the strength of an operant" ( $p$. 58). We must, therefore, provide some point in the model where we can take a measure of the rate of responding. It is obvious that that should be at the bottom of this process, after the flow of the reserve has become meted out into discrete responses. A meter is provided in Figure 1 in the form of a switch that operates a cumulative recorder. Rate of responding is inferred from the slope of the record.

Note that the first conduit out of the primary reservoir does not exit from the bottom of that vessel. This allows the possibility of "conditioning below zero," and thus building "up" a negative reserve. However this is only possible for respondent conditioning: "A negative reserve is impossible [in operant conditioning] because further elicitations without reinforcement are not available when the strength has reached zero" (p. 111).

Is it possible to reduce the reserve by punishing responses? Skinner argued that it was not, and that although some data suggested this possibility (Figure 45), when the experiment was replicated with milder punishment the effect was transitory. (Figure 50 suggests that this milder punishment may actually have been reinforcing, as does the account of another experiment that employed the same "aversive" stimulus: "When the slapping was omitted altogether, there was a reduction in rate; when all responses were again slapped, the rate increased rapidly"; p. 157.) 


\section{The Valves}

A number of operations change the proportionality between strength and reserve. How should these be represented? Because strength is the flow of responses out of the system, it must be done by changing the resistance to flow; in a hydraulic system that means valves. There are two possible locations for valves, the first controlling flow between the primary and secondary reservoirs and the second controlling flow between the secondary and tertiary reservoirs. Skinner did not make the locus of these effects clear, but spoke equivocally of "operations that affect the proportionality." However, there are two types of consequences that can be captured by valves in the two locations. The first of these is a reduction in flow that is not compensated for by a subsequent increase; the best example of this is changes due to modification of drive level. Decreases in drive close the first valve; as drive subsequently increases, responding increases; however, response rate never goes high enough to bring the envelope of the cumulative record to the height it might have been without the vicissitude in drive. Other "states of strength" that might affect flow at this point are drugs, illness, sleep, and age.

The other class of constraints on responding, exemplified by the removal of the operandum or emotional disruption, generates decreases in responding that are compensated for by subsequent increases in responding. Skinner's whole purpose in introducing the construct of the immediate reserve was to mediate such compensatory changes (p. 85). The envelope of the extinction curve was idealized as a smooth line that touched the actual record at a number of points, but was such that deviations were always below the envelope. Because the record usually seemed to recover from such deviations, some "memory" of where the unperturbed system should be was necessary. The secondary reservoir provides that. "When elicitation is continuous, the total reserve controls the process. When elicitation is interrupted, the immediate reserve is built up; and a period of increased activity is made possible when responding is resumed, until the total reserve again becomes the controlling factor" (p. 85). To convey the first assertion, I have made the primary valve and the conduit from primary to secondary reservoirs intrinsically smaller than that from secondary to tertiary, so that in the normal course of events the secondary reservoir will be relatively empty and the flow will be controlled by the head in the primary reservoir and the drive level (i.e., the reserve and the setting of the primary valve).

The secondary valve is the site at which numerous operations come to bear on behavior: Removal of the animal from the apparatus for an interval of time during the course of extinction permits replenishment of the immediate reserve, and that restocking gave rise to the phenomenon of spontaneous recovery. A similar effect was obtained by a locking of the response lever. Inhibition and repression were presumed to be compensated for, and thus must operate the secondary valve. Deviations in satiation curves caused by the increasing relative potency of other stimuli in the environment as the primary drive decreased were also compensated, and thus also operate the secondary valve. Two additional operations that appear to have their effect here are punishment and discrimination training.

Negative conditioning. Are there operations that decrease the size of the reserve without requiring the expenditure of responses? "Negative reinforcement" was used for operations we now call punishment, and two possible mechanisms were postulated-"negative conditioning" consisting of a reduction of the number of responses in the reserve, and emotional effects that reduced responding directly. Skinner then sketched a "conditioned emotional response" theory of punishment: Approaches to the lever that had been paired with shock elicit (through respondent conditioning) an emotional response, which depresses rate. In an experiment in which mild punishment (the level was made to slap the rat's paw) was applied to lever pressing, Skinner noted complete compensation in the number of responses eventually emitted. This clearly establishes the locus of such emotionally mediated depressive effects at the secondary valve. Skinner noted that stronger aversive stimulation might bring about "negative conditioning" but was dubious whether that would be the case (p. 159). As he summed up: "The experiments on periodic negative conditioning show that any true reduction 
in reserve is at best temporary and that the emotional effect to be expected of such stimulation can adequately account for the temporary weakening of the reflex actually observed" (p. 157; for consistency with his theoretical treatment in general, the words true reduction in reserve should be replaced with reduction of strength).

Skinner's model generally loçates emotional effects at the secondary valve (although I remind the reader again that Skinner himself never spoke in terms of valves or reservoirs), because he expected such effects to show a subsequent compensatory rebound, and the immediate reserve is the hypothetical construct Skinner invoked to explain deviations that show such compensation. But in some of his "punishment" experiments he did not see compensation. He hypothesized that that may have been the case either because compensation cannot hold over the 24-hr delay imposed in those particular experiments, or because punishment is more like reducing drive than it is like other emotions, and "reduced rate due to lowered drive is not compensated for subsequently" (p. 157). This latter explanation places the effects of punishment at the primary valve; but it is clear that Skinner believed compensation to be the general case for punishment. The first hypothesis (limited durability) saves these results for the model by in effect making the secondary reservoir permeable (as is the first), so that if the immediate reserve is not taken advantage of within several hours, it will dissipate. But that undoes the utility of the immediate reserve in explaining spontaneous recovery, which holds over interruptions of several days. However, because of the substantial possibility that these "mild punishments" were not at all punishing, the lack of compensation in these experiments should not be taken as a serious threat to Skinner's hypothesis that the effects of punishment were primarily emotional (i.e., did not decrease the reserve and were compensated).

Although Skinner's hypothesis may be saved by this argument, that does not mean that his hypothesis is correct. Subsequent research (e.g., Azrin \& Holz, 1966) has shown that the effects of punishment can be lasting. Those data might be taken to indicate that Skinner's original intuition was correct, and that the term "negative conditioning" should be rein- stated as the theoretical consequence of punishing operations (to the perpetual confounding of psychology students!). Alternatively, perhaps such traumatic stimuli just weld shut one of the valves. How do we know? How do we keep all this straight? One of the advantages of working with a physical model is that it stays in place for reference while we digress for analysis, as we have in the last paragraphs. Referring to Figure 1, we see that if severe punishment were best conceptualized as negative conditioning and acted by emptying the reservoirs, we should never be able to get the animal to respond again unless we refilled the reservoir via reinforcement. If punishment works by locking the primary valve where drive and fatigue operate, more drive or rest might enable responding; if it works at the secondary valve, desensitization of the emotional responses may be effective-and may vent a flood of repressed responses.

Discrimination training. A surprising and controversial postulate of the system concerns the nature of the "things" in the reservoir: "The operant reserve is a reserve of responses, not stimulus-response units" (p. 230). The Law of the Operant Reserve (pp. 229-230) states "The reinforcement of an operant creates a single reserve, the size of which is independent of the stimulating field but which is differentially accessible under different fields." The presentation or removal of discriminative stimuli operates one of the valves: "The discriminative field at the moment of emission acts as a sort of patterned filter: if it matches the field at the time of reinforcement, the rate of responding is maximal; if it does not, the rate is depressed" (p. 229). Which valve? He points to a cumulative record showing some compensation when the optimal filter is restored (although in this case he does not term it compensation); this would place the locus of the effect at the secondary valve. If the discriminative filter is placed at the secondary valve it might also permit the immediate reserve to mediate contrast effects (p. 175).

I say that this is controversial because we do not expect an animal whose key pecking has been thoroughly extinguished in the presence of a red stimulus to have key pecking that had been established in the presence of a green stimulus also thereby extinguished 


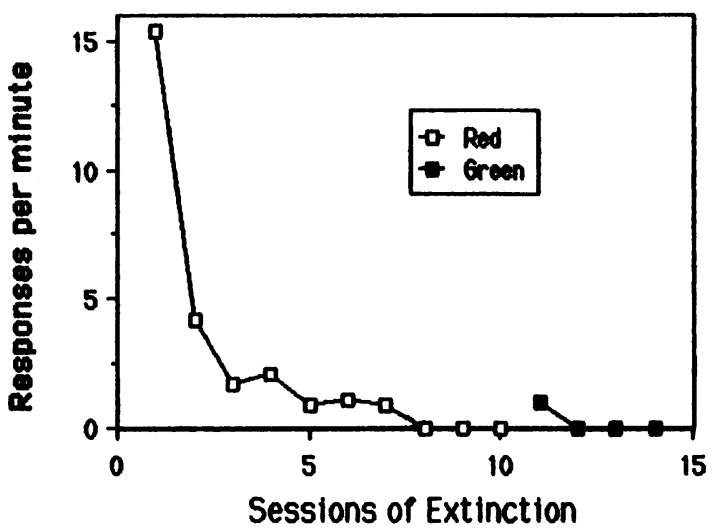

Fig. 2. Response rate of a pigeon trained on equal probabilistic reinforcement schedules with red and green keylights, with responding then extinguished for 10 sessions in the presence of the red light and then for four sessions in the presence of the green light.

("Even with a sub-optimal filter all responses would be emitted if time allowed"; p. 229). Skinner recognized the difficulties this postulate entailed ("[It] throws considerable weight upon the response alone, and this may seem to weaken any attempt to group operants under the general heading of reflexes"; $p$. 230), but apparently felt himself forced to this position by his insistence that the discriminated operant was not a reflex but rather a pseudo-reflex (p. $236 \mathrm{ff}$.), and thus not the type of entity that could be stored in a reserve. To demonstrate the inaccuracy of this hypothesis, I asked David MacEwen to condition a pigeon to respond on a multiple (random ratio 20 , random ratio 20 ) schedule, in which key pecks to a red key would be followed by food $5 \%$ of the time and key pecks to a green key would be followed by food $5 \%$ of the time. The key colors alternated after each reinforcement. After 20 sessions, responding was stable in each component at about 74 responses per minute. Dave then put the pigeon in the chamber for ten 40-min sessions with only the red keylight on and no food available. Responding decreased to zero pecks in each of the last three sessions. He then turned the keylight color to green to track the second extinction process. Figure 2 shows the results. Skinner was right after all! The number of responses emitted in the second extinction was miniscule compared to the number in the first extinction. Alternative explanations could of course be foundthe keylight was only a small part of a complex stimulus that had been largely extinguished, arousal conditioned to the chamber had extinguished, and so on. But I prefer to think that Skinner had at least in part succeeded in generating "a system of behavior which has a structure determined by the nature of the subject matter itself' (p. 434), and that structure could be used to make novel and counterintuitive predictions.

\section{Straining the Reserve}

It is possible for animals to respond faster than the first conduit can routinely support. In this case the secondary reservoir is drained and rates decrease to that controlled by the first conduit and valve. A period of nonresponding will permit the secondary reservoir to replenish, and responses to be emitted at a high rate again. One cause of nonresponding is the imposition of the discrimination filter; that is, the constriction of the secondary valve due to a nonoptimal stimulus field. One instance in which this may occur is on fixedinterval and fixed-ratio schedules immediately after reinforcement, "since one reinforcement never occurs immediately after another. A reinforcement therefore acts as $S^{\Delta}$... Aside from the weakening of $\mathrm{S}_{\text {reinf }}$ another factor tends to strengthen the operant during the pause, namely the recovery of the reserve from the strain imposed upon it by the preceeding run" (pp. 288-289).

\section{Partial Reinforcement Effects}

A problem for the reflex reserve was its expansion by schedules that reinforced responses only after fixed periods (periodic reinforcement) or after a number of responses had been made (ratio reinforcement). How could this happen? At one point Skinner suggested that the mechanism was the increased efficiency of periodic reinforcement: "The most efficient way of building up a reserve with a given number of reinforcements is to administer them periodically" (p. 137). This follows from the earlier statement that reinforcers are less efficient when the reserve is close to its maximum. However that statement doesn't go far enough: "No amount of continuous reconditioning will yield an extinction curve of the height obtained through even small amounts of periodic reconditioning" (p. 138). Clearly the size of the reservoir (i.e., the maximum size of the reserve) seems 
to be affected by intermittent reinforcement schedules. Skinner solved the problem for ratio schedules by a response-unit hypothesis: "When a reinforcement depends upon the completion of a number of similar acts, the whole group tends to acquire the status of a single response, and the contribution to the reserve tends to be in terms of groups" (p. 300). This is a plausible hypothesis, although it must leave us a bit confused about what we are measuring at the output of the tertiary reservoir: At least under ratio schedules of reinforcement, lever presses have become molecular acts, whereas it is groups of them that are responses. Response rate as the fundamental datum retreats a step from observability, because it is acts, not responses, that get counted. But this should not prove a severe problem for our science; Skinner was correct in recognizing that the unit of behavior is to be defined "at levels of specification marked by the orderliness of dynamic changes" (p. 40). Direct observability, although desirable, is secondary to this criterion.

We need not abandon the assumption of a fixed size for the reservoir if we are willing to assume that the effect of ratio reinforcement is on the tertiary reservoir, or on the relation between that and the meter. Which is the best assumption? That depends on which dovetails best with the assumptions needed to accommodate other effects, and which affords the most new predictions as its by-product. Balancing such considerations is the heart of theory construction.

\section{Evaluation}

There were many strengths and a few weaknesses in Skinner's system of behavior. He developed the system as he went, and the relationship between the parts was not always clear (Verplanck, 1954). The greatest tragedy is that it was published just before the second world war, and there were few students around who were able to perfect the theory. Skinner had no Spence. He himself was apparently burned out on the monumental effort-a classic case of ratio strain. His philosophical orientations (a Machean positivism) and his technical limitations (his lack of mathematical skills) hobbled him as they might not have hobbled a colleague or student (who, of course, would not have possessed Skinner's unique combination of abilities). He rec- ognized the difficulties of his system but he was not up to remedying them, and he had gotten little recognition and few other reinforcers for what was truly a magnificent exercise in theory development. He received instead superficial criticism on the very points he was least able to defend (Ellson, 1939). After 1938 he faded out the reflex reserve as a central unifying concept. But Skinner's criticisms of theory were never aimed against the type of system he developed in this book. He repudiated the assumption of alternate structures as the causes of behavior, and would have blanched if someone misunderstood him to say that behavior occurred in thus-and-such a pattern because of the properties of some internal system of pools. The reification of the reserve as the contents of a reservoir is an aide memoire, a sketch drawn upon a protean chalkboard that can be given properties congruent with those of the behavioral system - in a word, a model, and only that.

\section{Reconstruction}

There are few structures more deserving of restoration than Skinner's system of behavior. It is a worthy project, for it would provide our community with the type of theory we have all along needed-a blueprint for theory hidden in a time capsule called The Behavior of Organisms. But that is too large a project for one person. Instead, I will do a few easy things: I have already cleared away some of the dust; now I shall try to demonstrate that the underlying structure is sound and relevant to our times. I shall do this not by mapping the physical model to current data, but rather by identifying some of its mathematical properties and relating them to other models. This is not ideal, because these models may be inaccurate. But they are the products of attempts to find and characterize structure in behavior. If the characterizations are consonant with the data and with Skinner's theory, then at least we have accomplished a plausibility proof.

\section{MATHEMATICAL MODELS}

These are easy to construct, because Skinner's verbal descriptions of the system were couched in precise, quasi-mathematical form: "At any point the rate of responding may be assumed to be roughly proportional to the 
existing reserve. At the beginning of extinction the reserve and the rate are both maximal. As responses occur the reserve is drained and the rate declines" (pp.. 83-84). If we signify the maximum reserve as $M$, the number of responses emitted as $r$, and the size of the reserve as $R=M-r$, then we may represent these sentences as:

$$
\mathrm{d} r / \mathrm{d} t=k R,
$$

and,

$$
R\left(t_{0}\right)=M,
$$

where $\mathrm{d} r / \mathrm{d} t$ is the rate of responding, $R$ is the size of the reserve, and $k$ is the constant of proportionality. (Strictly, responses are discrete, as are reinforcers; Equation 1 should be a difference equation. The assumption of continuity makes it possible to derive standard forms, and thus facilitates this exposition.)

Draining the reservoirs. As it stands, Equation 1 predicts that if we plot the response rate as a function of the number of responses that have yet to be emitted in extinction (or, rate against number already emitted), we should see a straight line. I do not know of any such plots. However, it is simple to manipulate Equation 1 to derive predictions of more familiar graphs. Substituting $M-r$ for $R$ in the right side of Equation 1, we may rearrange terms and integrate. Given the boundary condition of Equation 2 we obtain:

$$
r=M\left(1-e^{-k t}\right) .
$$

This equation describes the familiar concave curve that approaches the maximum of the reserve asymptotically as $t$ gets indefinitely large. It is the equation that Skinner should have used for the envelopes of all of his extinction curves (rather than the logarithmic functions that he did use, and which have no logical justification in his system). Curiously, he knew Equation 3, for he cited Bousfield's use of it to describe satiation curves (p. 351). Furthermore he himself drew such curves in Figure 134 and identified them as "based on the assumption that the rate of responding is proportional to the responses still remaining in the reserve and that the effect of drive is to change the proportionality." He noted that the curves fit the data well, but he did not associate the curves with their equation. (For an informative account of Skinner's early search for quantitative order and the development in his metatheory before 1938 , see Coleman [1984, 1987].)

"The slope of the envelope of the extinction curve gives the maximal rate of emission at any point" (p. 84). We obtain the slope of Equation 3 by taking its derivative with respect to time. That is:

$$
\mathrm{d} r / \mathrm{d} t=(M / k) e^{-k t} ;
$$

response rate should decline as an exponential function of time. This is the usual form of the extinction curve when response rates are sufficiently below their ceiling (see, e.g., Figure 2). But at very high rates there is competition for expression of the reserve. This is already captured in Figure 1 by the finite size of the conduit between reservoirs. If we assume that competition increases linearly with rate of emission, we obtain the logistic function (Killeen, 1982):

$$
\mathrm{d} r / \mathrm{d} t=1 /\left(\delta+k^{\prime} e^{k t}\right),
$$

which provides a good representation of the extinction process. When the amount of restriction in the conduits $(\delta)$ is small, Equation 5 becomes equivalent to Equation 4 .

The smooth exponential decay function assumes that there is no fiddling with the valves during the process. As Skinner noted, on first extinction failure to reinforce will generate emotional reactions that will cause depressions in rate that are subsequently compensated (p. 76; the extinction curves after periodic reconditioning are smooth because the emotional effects have had ample opportunity to adapt out; p. 133). The smooth envelopes he draws thus depict the flow past the primary valve. This may have been the better place to locate response strength, because it may also have been upstream from the point at which response units are modified. It would have required treating response strength as an intervening variable. However, as it stands he left strength identical to the dependent variable response rate, and therefore uselessly redundant.

Filling the reservoirs. "Successive reinforcements are less and less effective in adding to the total as the maximal value is approached"; the simplest instantiation of this is:

$$
\mathrm{d} R=c(M-R) \mathrm{d} n
$$


where $\mathrm{d} n$ is the change in number of reinforcers, and $c$ is a constant of proportionality. Solution of Equation 6 yields

$$
R=M\left(1-e^{-c n}\right) \text {. }
$$

Again, this is a familiar form. Hull used it for the growth in habit strength as a function of the number of reinforcements (1943, p. 119). It is a basic equation in the classical mathematical models of learning (see, e.g., Hilgard \& Bower, 1966). It is a direct implication of Rescorla and Wagner's (1972) model, and has made its most recent appearance as the "generalized delta rule" of neural modelers (e.g., Stone, 1986). Although Equations 3, 4, 5, and 7 are derived from a deterministic physical model (BharuchaReid, 1960, chap. 6; Jones, 1973), they also represent probabilistic models of the learning process (e.g., Estes, 1959; Killeen, Hanson, \& Osborne, 1978).

There are many other hypotheses and semiquantitative models to be found in $\mathrm{The} B e$ havior of Organisms (e.g., the extinction ratio), as there are other modern mathematical models of operant responding. In some cases the correspondence between Skinner's models and the modern ones are clear. Skinner adumbrates frustration theory (p. 133; cf. Amsel, 1962), overshadowing ("A discriminated response contributes little or nothing to the reserve" p. 132), instant of response ("We need to find the point in the sequence of events called 'the response' from which measured intervals show the greatest simplicity in their effect" (p. 145); cf. Shimp, 1979), dynamic equilibria ("The constant rate represents a balance between input and output" p. 145; cf. McDowell \& Kessel, 1979; Myerson \& Miezen, 1980), an autocatalytic theory of responding (pp. 299-300; cf. Hanson \& Killeen, 1981; Keller, 1980) and many other modern approaches which could be seen as perfections of his sketches. Conversely, some recent developments would change some of his operating assumptions. Nevin (1988) has recently suggested that partial-reinforcement schedules may not actually increase resistance to extinction. He has proposed a measure of strength that is essentially "resistance to change" (Nevin, Mandell, \& Atak, 1983)-this may be viewed as moving the measure of strength from flow at the bottom of the tertiary reserve to pressure at the primary valve. If the shaping effect of contingencies is placed downstream at the tertiary reservoir, it may be found that contingencies form response units and determine response rate, but that they have no effect on resistance to change (see Nevin, Smith, \& Roberts, 1987). In the case of concurrent reinforcement, one can easily imagine two reservoir systems connected at the tertiary reservoir and competing for expression through the siphon; however, in 1938 "The stage of combining two reflexes in order to observe the resultant behavior has not been reached" p. 46). I suspect that the combination might be captured in part by McDowell's (1980) linear-system model, which also would easily incorporate the lag in the system from input to output. Skinner's concept of reserve is closely analogous to my concept of arousal (Killeen, 1979), down to many of the exemplary experiments on single-trial conditioning, exponential-integral cumulation curves, exponential extinction curves, and other details. One could go on; how could it be that so seminal a system as that expounded in The Behavior of Organisms could impart so much inspiration for, and yet so little direction to, the half century of research since its publication?

\section{A MODEL FOR US}

Quaint, perhaps, but why all the fuss, when the reflex reserve is of only historical interest? But it is not of only historical interest. The power and coherency of Skinner's theory make his work in 1938 of contemporary relevance, both for substantive scientific reasons and for procedural, metascientific ones. He had a theory that anticipated many contemporary models. He generated many creative hypotheses concerning the nature and determinants of behavior. He wrestled with the fundamental issue of determining a unit of behavior in a more sophisticated manner than has anyone since. He performed experiments to test specific aspects of his model and to determine what other aspects were needed (see, e.g., his experiments to test the notion of disinhibition on pp. $98 \mathrm{ff}$ ). He recognized that behavior is about dynamic changes, and that that recognition must guide the selection and the interpretation of data. He employed a model that was intrinsically dynamic. $\mathrm{He}$ was truly building a system. 
What did Skinner have going for him? He had a physical model, in terms of which he interpreted and whose character summarized his experimental results. One of the most important criteria for acceptance of a model in the physical sciences was that it be anshaulich-visualizable (Miller, 1984), as was Skinner's hydraulic system. If we look at the current renaissance of modeling in the behavioral community (see, e.g., Nevin, 1984), we see numerous creative accomplishments. But we do not have the sense that a system is being constructed. Fine points are debated while commonalities are ignored. When resolutions are attained, they are left to languish in verbal form, to be resurrected ever less frequently in periodic reviews performed by graduate students to satisfy academic requirements. We should learn from the history of the more advanced sciences, and from the practice of the early Skinner. (Later, Skinner was dissuaded from the use of such constructs by Kantor, who was a philosopher, not a scientist; Skinner, 1966/1938.) The early Skinner may have been overshadowed by the later one, but he was never outshone by him.

What else did Skinner have? Deliberation that seems rare in modern times. When not required to immediately go public with the interpretation of every experiment, we are freer to compile our results into a corpus that makes more sense overall. Responsibility for these contingencies rests finally with our journals, which should discourage less than systematic approaches to an issue. This stricture is made tolerable if we are not called upon to generate the whole system ourselves, but can view our contributions in terms of the elaboration of a communal system.

Skinner appreciated theory. His words are a mother's admonition to a delinquent but cherished son. "Experimental psychology is properly and inevitably committed to the construction of a theory of behavior. A theory is essential to the scientific understanding of behavior as a subject matter" (Skinner, 1947/ 1972, p. 302). But for Skinner, like Stevens, theory had to reside on the same level as the data (p. 441); that is, theory had to be "bottom-up." The essence of science was the articulation of data by theory, of empirics by schemata (Killeen, 1976; Williams, 1986).

How shall we construct our theory? I propose that we start by fully restoring Skinner's reservoirs, fitting them to recent facts, relating them to other models. Of course there will be limits to the utility of any system such as the reserve; but the exercise will clarify the relation of the new data to what came before. I propose that we deemphasize the often counterproductive philosophy of falsificationism, and work together with a new philosophy of constructivism. Science is not a zero-sum game; we shall not establish a system of behavior by undermining "theirs" and offering "ours" instead, but only by critically selecting the best of theirs and building on it. Within only a few years we shall have developed a system whose structure is closely parallel with the subject we study, and whose models will display most of what we know about the dynamics of behavior. Their format will be intuitively accessible to all, and each of us can play a part, according to our own skills, in contributing to this edifice.

\section{REFERENCES}

Amsel, A. (1962). Frustrative nonreward in partial reinforcement and discrimination learning: Some recent history and a theoretical extension. Psychological Review, 69, 306-328.

Azrin, N. H., \& Holz, W. C. (1966). Punishment. In W. K. Honig (Ed.), Operant behavior: Areas of research and application (pp. 380-447). New York: Appleton-Century-Crofts.

Bharucha-Reid, A. T. (1960). Elements of the theory of Markov processes and their applications. New York: McGraw-Hill.

Coleman, S. R. (1984). Background and change in B. F. Skinner's metatheory from 1930 to 1938 . Journal of Mind and Behavior, 5, 471-500.

Coleman, S. R. (1987). Quantitative order in B. F. Skinner's early research program, 1928-1931. Behavior Analyst, 10, 47-65.

Ellson, D. G. (1939). The concept of reflex reserve. Psychological Review, 46, 566-575.

Estes, W. K. (1959). The statistical approach to learning theory. In S. Koch (Ed.), Psychology: A study of a science: Vol. 2. General systematic formulations, learning, and special processes (pp. 380-491). New York: McGraw-Hill.

Hanson, S. J., \& Killeen, P. R. (1981). Measurement and modeling of behavior under fixed-interval schedules of reinforcement. Journal of Experimental Psychology: Animal Behavior Processes, 7, 129-139.

Hilgard, E. R., \& Bower, G. H. (1966). Theories of learning (3rd ed.). New York: Appleton-Century-Crofts.

Hull, C. L. (1943). Principles of behavior. New York: Appleton-Century-Crofts.

Jones, R. W. (1973). Principles of biological regulation. New York: Academic Press.

Keller, K. J. (1980). Inhibitory effects of reinforcement and a model of fixed-interval performances. Animal Learning \& Behavior, 8, 102-109. 
Killeen, P. R. (1976). The schemapiric view: Notes on S. S. Stevens' philosophy and Psychophysics. Journal of the Experimental Analysis of Behavior, 25, 123-128.

Killeen, P. R. (1979). Arousal: Its genesis, modulation and extinction. In M. D. Zeiller \& P. Harzem (Eds.), Advances in analysis of behavior (Vol. 1): Reinforcement and the organization of behavior (pp. 31-78). Chichester, England: Wiley.

Killeen, P. R. (1982). Incentive theory. In D. J. Bernstein (Ed.), Nebraska symposium on motivation, 1981: Vol. 29. Response structure and organization (pp. 169216). Lincoln: University of Nebraska Press.

Killeen, P. R., Hanson, S. J., \& Osborne, S. R. (1978). Arousal: Its genesis and manifestation as response rate. Psychological Review, 85, 571-581.

McDowell, J. J. (1980). An analytic comparison of Herrnstein's equations and a multivariate rate equation. Journal of the Experimental Analysis of Behavior, 33, 397-408.

McDowell, J. J. (1988). Behavior analysis: The third branch of Aristotle's physics. Journal of the Experimental Analysis of Behavior, 50, 297-304.

McDowell, J. J, \& Kessel, R. (1979). A multivariate rate equation for variable-interval performance. Journal of the Experimental Analysis of Behavior, 31, 267283.

Miller, A. I. (1984). Imagery in scientific thought. Boston: Birkhäuser.

Myerson, J., \& Miezin, F. M. (1980). The kinetics of choice: An operant systems analysis. Psychological Review, 87, 160-174.

Nevin, J. A. (1984). Quantitative analysis. Journal of the Experimental Analysis of Behavior, 42, 421-434.

Nevin, J. A. (1988). Behavioral momentum and the partial reinforcement effect. Psychological Bulletin, 103, 44-56.

Nevin, J. A., Mandell, C., \& Atak, J. R. (1983). The analysis of behavioral momentum. Journal of the Experimental Analysis of Behavior, 39, 49-59.

Nevin, J. A., Smith, L. D., \& Roberts, J. (1987). Does contingent reinforcement strengthen operant behavior? Journal of the Experimental Analysis of Behavior, 48, 17-33.
Pauly, P. J. (1987). Controlling life: Jacques Loeb and the engineering ideal in biology. New York: Oxford University Press.

Rescorla, R. A., \& Wagner, A. R. (1972). A theory of Pavlovian conditioning: Variations in the effectiveness of reinforcement and nonreinforcement. In A. H. Black \& W. F. Prokasy (Eds.), Classical conditioning II: Current research and theory (pp. 64-99). New York: Appleton-Century-Crofts.

Shimp, C. P. (1979). The local organization of behaviour: Method and theory. In M. D. Zeiler \& P. Harzem (Eds.), Advances in analysis of behaviour: Vol. 1. Reinforcement and the organization of behaviour (pp. 261-298). New York: Wiley.

Skinner, B. F. (1938). The behavior of organisms. New York: Appleton-Century.

Skinner, B. F. (1947). Experimental psychology. In W. Dennis, B. F. Skinner, R. R. Sears, E. L. Kelly, C. Rogers, J. C. Flanagan, C. T. Morgan, \& R. Likert, Current trends in psychology (pp. 16-49). Pittsburgh, PA: University of Pittsburgh Press. (Reprinted as "Current trends in experimental psychology" in Skinner, B. F. [1972]. Cumulative record: A selection of papers [3rd ed., pp. 295-313]. New York: AppletonCentury-Crofts.)

Skinner, B. F. (1966/1938). Preface to the seventh printing of The behavior of organisms. New York: Appleton-Century-Crofts.

Stone, G. O. (1986). An analysis of the delta rule and the learning of statistical associations. In D. E. Rumelhart, J. L. McClelland, and the PDP Research Group (Eds.), Parallel distributed processing: Explorations in the microstructure of cognition: Vol. 1. Foundations (pp. 444-459). Cambridge, MA: MIT Press.

Verplanck, W. S. (1954). Burrhus F. Skinner. In W. W. Estes, S. Koch, K. MacCorquodale, P. E. Meehl, C. G. Mueller, Jr., W. N. Schoenfeld, \& W. S. Verplanck (Eds.), Modern learning theory (pp. 267316). New York: Appleton-Century-Crofts.

Williams, B. A. (1986). On the role of theory in behavior analysis. Behaviorism, 14, 111-124.

Zuriff, G. E. (1985). Behaviorism: A conceptual reconstruction. New York: Columbia University Press. 